\title{
ALUminating the path of atherosclerosis progression: chaos theory suggests a role for Alu repeats in the development of atherosclerotic vascular disease
}

Short running head: Alu repeated elements and the mechanisms of atherosclerosis .

Miguel Hueso ${ }^{1 *}$ (mhueso@idibell.cat),

Josep M Cruzado ${ }^{1}$ (jmcruzado@bellvitgehospital.cat),

Joan Torras ${ }^{1}$ 15268jta@ comb.cat),

Estanislao Navarro ${ }^{2}$ (estanis.navarro@gmail.com).

1-Department of Nephrology. Hospital Universitari Bellvitge, and Bellvitge Research Institute (IDIBELL). L'Hospitalet de Llobregat. Spain

2- Independent Researcher

*Corresponding author:

Miguel Hueso MD.

Department of Nephrology. Hospital Universitari Bellvitge and Bellvitge Research Institute (IDIBELL)

C/ Feixa llarga, s/n; L'Hospitalet de Llobregat, 08907 Barcelona,. Spain.

Fax number:+34932607603, Telephone number:+34932607602

Email: mhueso@idibell.cat 


\begin{abstract}
Atherosclerosis (ATH) and Coronary Artery Disease (CAD) are chronic inflammatory diseases with an important genetic background which derive from the cumulative effect of multiple common risk alleles, most of them located in genomic non-coding regions. These complex diseases behave as non-linear dynamical systems that show a high dependence on their initial conditions, so that long-term predictions of disease progression are unreliable. One likely possibility is that the non-linear nature of ATH could be dependent on non-linear correlations in the structure of the human genome. In this review we show how Chaos theory analysis highlighted genomic regions that shared specific structural constraints that could have a role in ATH progression. These regions were shown to be enriched in repetitive sequences of the Alu family, genomic parasites which colonized the human genome, which show a particular secondary structure and have been involved in the regulation of gene expression. We also review the impact of Alu elements on the mechanisms that regulate gene expression, especially highlighting the molecular mechanisms by which the Alu elements could alter the inflammatory homeostasis. We devise especial attention to their relationship with the lncRNA ANRIL, the strongest risk factor for ATH, their role as miRNA sponges, and their ability to interfere with the regulatory circuitry of the $\mathrm{NF}-\kappa \mathrm{B}$ response. We aim to characterize ATH as a non-linear dynamic system in which small initial alterations in the expression of a number of repetitive elements are somehow amplified to reach phenotypic significance.
\end{abstract}




\section{KEYWORDS:}

Atherosclerosis, Cardiovascular Disease, Chaos Theory, non-coding RNAs, Aluelements, NF- $\kappa \mathrm{B}$, miRNA, miRNA sponges.

\section{LIST OF ABBREVIATIONS:}

AS-RNAs: antisense transcripts from coding regions

ASVD: Atherosclerotic Vascular Disease

ATH: Atherosclerosis

BM-EPCs: Bone Marrow-derived Endothelial Progenitor Cells

CAD: Coronary artery disease

cirRNAs: circular ncRNA

CKD: Chronic Kidney Disease

EC: Endothelial Cells

eQTL: Expression Quantitative Trait Locus

ECM: Extracellular matrix

ESRD: End Stage Renal Disease

GWAS: Genome-Wide Association Studies

LINE: Long Interspersed Nuclear Element

ncRNA: non-coding RNA

lncRNA: long non-coding RNA

lincRNAs: long intergenic ncRNAs

MACE: Major Adverse Cardiovascular Event

miRNA: micro RNA

MP: Microparticles

ncRNAs: non-coding RNAs

NO: Nitric Oxide

piRNAs: Piwi-interacting RNAs

RMC: Renal Microcirculation

ROS: Reactive Oxygen Species

SMC: Smooth-Muscle Cells

SNPs: Single-Nucleotide Polymorphisms

SINE: Short Interspersed Nuclear Element

\section{LIST OF GENES}

Ang II: Angiotensin II

ACE: Angiotensin Converting Enzyme

ANRIL/CDKN2B-AS1: Antisense Noncoding RNA in the INK4 Locus, CDKN2B AntiSense 1

BAFFR: B cell-Activating Factor belonging to the TNF Family Receptor

BCR: B Cell Receptor

ETA: endothelin A

ETB: endothelin B2

FOXO: Forkhead box O transcription factor

HIF: Hypoxia-Inducible Factor

HIF-PHDs: HIF-Prolyl Hydroxilase Domain enzymes

HRMs: Hypoxia-Regulated miRNAS

IKK: IкB Kinase

LTbR: LymphoToxin beta Receptor

MMP-9: Matrix Metalloproteinase-9 
NEMO: NF- $\kappa$ B Essential Modulator

NIK: NF- $\kappa \mathrm{B}$ Inducing Kinase

NF- $\kappa B$ : Activated Nuclear Factor-kB

NAD(P)H: Nicotinamide Adenine Dinucleotide Phosphate

PCAM1: Platelet Endothelial Cell Adhesion Molecule

PODXL: Podocalyxin

PRC: Polycomb Repressive Complexes

PRRs: Pattern-Recognition Receptors

RAAS: Renin-Angiotensin Aldosterone System

RANK: Receptor Activator of NF- $\kappa$ B

RYBP: RING1 and YY1 Binding Protein

STAT1: Signal Transducers and Activators of Transcription-1

TCR: T Cell Receptor

TLRs: Toll-like receptors

TNFAIP3: TNF alpha Induced Protein 3

TNFR: Tumor Necrosis Factor Receptors

TSSs: Transcription Start Sites

TWEAK: TNF related WEAK inducer of apoptosis

VLA-4: Very Late Antigen-4

VCAM-1: Vascular Cell Adhesion Molecule-1 


\section{1.- THE COMPLEX CAUSALITY OF CHRONIC KIDNEY DISEASE CALLS FOR NEW BIOMARKERS OF DISEASE PROGRESSION AND RISK TO ADVERSE CARDIOVASCULAR EVENTS}

Major adverse cardiovascular events (MACEs) are the main cause of death in patients with Chronic Kidney Disease (CKD), although these are extremely difficult to predict. Consequently, validation of MACE biomarkers is urgently required to follow disease progression while new therapies have to be developed to offer new, personalized treatments to CKD patients. Globally, new concepts and ideas have to be added the research mainstream on CKD to ultimately lead to new approaches on MACE prevention.

Vascular dynamics is a highly dynamical system that shows time-dependent functional changes which are critically dependent on the interaction with different physical forces. These can be extra-tissular (as blood flow oscillations, arterial pressure, etc.) or intra-tissular (as calcifications, tissue thickness, presence of white cell infiltrates, etc.), but all of them show an unpredictable evolution caused by the appearance of minor interferences with the potential to produce unforeseen outcomes. Furthermore, vascular dynamics could be considered as a "chaotic" system whose evolution demonstrates a very sensitive dependence on its initial conditions and follows an uncertain, non linear progression [1-3], and there are a number of reports that back this hypothesis In this regard, Bruschke et al., showed that atherosclerosis (ATH) progression in coronary arteries was a highly unpredictable process which followed a nonlinear course [4] while other studies showed that arteries exhibited a non-linear, elastic behavior [5]. Furthermore, carotid arteries exhibit nonlinear variations of circumferential stress and tangent elastic moduli within the normal pressure range [6], and the evolution of buckling pressures of arteries under pulsatile pressure conditions could be accurately described by a non-linear model of elasticity [7]. Lastly, non-linear models have been also used to study the effects of luminal stenosis (and the plaque morphology) on plaque stability [8] or the interaction between the elastic layer (ECM cap) and the rigid calcified cells [9].

Most of the above studies have characterized the chaotic behavior of ATH by uniquely taking into account the role of the blood flow physics in the onset and progression of the disease. Nevertheless, there are hints that the non-linear progression 
of ATH disease could be also derived from specific features in the genome of the tissues involved in ATH, although it is difficult to envision how differential dynamics could be generated in a structure so homogeneous and tightly controlled as the mammalian nucleus. In this regard, Xiao et al., used a nonlinear prediction method, derived from chaos theory, to analyze the sequence of the $\beta$-globin locus and highlighted a subset of genomic sequences with novel deterministic structures and nonlinear correlations essentially different to those of exonic and intronic sequences (see [10], and section 3 for a more in deep discussion on the topic). These sequences corresponded to members of the Alu family of repeated elements, i.e. short DNA sequences [11] involved in the regulation of gene expression [12], that are pervasively transcribed in a number or physiological and clinical conditions [13-15] and have been associated to human diseases and genetic disorders [16, 17].

The non-linear structural features of Alu elements make worth studying the potential involvement of these repeated sequences in the generation of a chaotic progression during ATH development. In this review, we will study the possible relationship of Alu repeats with the onset and evolution of ATH, specifically focusing in different structural and/or functional features of Alu elements that could contribute to the non-linear progression of ATH, such as: (i)- the potential of Alu transcripts to act as miRNA sponges and hence to impact on general levels of mRNA expression, (ii)- their ability to generate new regulatory networks through retrotransposition to gene regulatory sites, and (iii)- their disruptive effect on the function of the CVD-associated lncRNA ANRIL, one of the strongest risk factors known for ATH.

\section{2.- Alu REPEATED ELEMENTS: UNWANTED PLAYERS IN THE GENE EXPRESSION GAME.}

One of the surprises that have arised from the systematic sequencing of different transcriptomes has been the discovery of a plethora of transcribed non-coding RNAs (ncRNAs) which corresponded to genomic regions previously known as "junk DNA". Without being exhaustive, these ncRNAs have been classified in 3 basic categories: $(i)$ housekeeping RNAs (rRNAs, tRNAs, snRNAs and snoRNAs), (ii) short ncRNAs (less than 200-300 nt) that include microRNAs (miRNAs), Piwi-interacting RNAs (piRNAs), and retrotransposon-derived ncRNAs such as SINEs (Short Interspersed Nuclear Elements), and (iii) long non-coding RNAs (lncRNAs, greater than $200 \mathrm{nt}$ ), which can 
be further divided into intronic long intergenic ncRNAs (lincRNAs), antisense transcripts from coding regions (AS-RNAs, which do not encode proteins), circular ncRNA (cirRNAs), LINES (Long Interspersed Nuclear Elements) etc, [18].

At the genomic DNA level, the most numerous group of genes encoding ncRNAs is that of the Alu repeats, members of the SINE family. Alu elements are dimeric, over 300 bp-long, retrotransposons composed by two arms separated by an Arich stretch. Alu repeats also include a bipartite Polymerase III internal promoter at the 5 ' end of left arm and a short poly-A tail at the 3' end of the right arm [12] (Figure 1). Alu repeats can be considered as highly successful genomic parasites which have colonized the human genome through cycles of retrotranscription (RNA to cDNA), insertion (cDNA into genomic DNA) and transcription (DNA to RNA), to the extent that approx. one million copies can be currently detected in the human genome [19]. This means that over $10 \%$ of the human genome is composed by Alu repeats, especially present in gene-rich regions, and that circa $30 \%$ of human genes harbour a copy of an Alu element [20]. Based on their evolutionary history, Alu elements have been classified in 12 subfamilies [21] from which only one is currently transpositionally active while the others have been inactivated, mainly by $5^{\prime}$ truncation but also by sequence degeneration [22]. Alu elements are non-autonomous, so that their reverse transcription and integration in the genome requires the protein machinery of other autonomous retrotransposons such as LINEs (Long Interspersed Nuclear Elements), although under normal conditions these are also repressed in the human genome, mostly through promoter methylation $[23,24]$, thus contributing to the silencing of Alu elements.

It has been known for long that Alu elements do play significant roles in the regulation of gene expression as well as in the maintenance of genomic integrity. Since Alu elements are usually in the neighbourhood of gene-rich regions, these repeated elements have been shown to impact the regulation of gene expression at the transcriptional as well as the post-transcriptional level through a number of different mechanisms [25]. At the transcriptional level, Alu repeats can be transcribed by RNA polymerase III (Pol III) from its endogenous internal promoter in response to cellular stress, giving rise to "free" Alus in the form of individual Alu RNA sequences which can repress RNA polymerase II-mediated transcription by binding to the Pol II initiation 
complex [12,26]. Much interestingly, a number of "immobilized" Alu elements have been detected in mature mRNAs, usually in their 5' or 3' UTRs [12], with their levels being subjected to regulation since there are reports of their downregulation in cancer cells [27], and concatemers of individual Alu-RNAs of yet unknown function have been detected and cloned also in cancer cells [15].

On the other hand, a number of reports have shown that Alu elements have the potential to also modify the maturation process of mRNAs. In this sense, many Alu elements are detected in intronic regions [28] where they can provide new signals to originate alternative mRNA splicings or even exon skipping [29]. On the other hand, intronic Alus can be incorporated to mature mRNAs as a "bona fide" exon by itself (Alu exonization) or after retaining part of the neighbor intron (Alu-dependent intronic retention) [30]. Finally, Alu elements have been also considered as probable miRNA targets, likely acting as "miRNA sponges" [31] (see Section 6.2), and have been involved in regulating the function of circular RNAs [20], or in the regulation of mRNA stability [11]. In resume, due to their high number of copies, their internal promoters and their embedding in mature transcripts, Alu elements can impact on most of the mechanisms regulating RNA expression.

\section{3.- MULTIFRACTAL AND CHAOS THEORY ANALYSIS OF THE HUMAN GENOME POINT OUT TO THE INVOLVEMENT OF Alu ELEMENTS IN THE DEVELOPMENT OF COMPLEX, NON-LINEAR HUMAN DISEASES}

\subsection{Chaos theory provides tools to for the analysis of global genomic signatures}

The human genome is one of the most intricate molecular machines known and many different approaches have been used to study and analyze its complexity. Chaos theory and the chaos game representation (CGR) are two mathematical tools widely used to characterize highly complex systems. CGR, an implementation of chaos theory and chaotic dynamics, is an algorithm that has been used for the graphical representation of DNA sequences [32]. The output of a CGR representation is a scatter plot in which each point of the plot corresponds to one base of the sequence, thus producing a complex picture of the DNA sequence in which local and global patterns of sequential structure can be defined [32]. In this sense, the CGR would represent either statistical properties of base frequencies as intrinsic properties of the DNA sequence itself [32]. The main interest of CGR plots and its developments [33] rely in that these 
reduce complex DNA sequences into visual patterns that facilitate comparative studies of genomic signatures, as well as the analysis of characteristic sequence motifs [34]. In this way, CGR plots have been used to determine the degree of variability within and between genomes [35] or to compare two entire genomes for mismatches, insertions, deletions or shuffles [36-37].

Images produced by the CGR can be further studied with methods derived from fractal geometry (multifractal analysis) [35]. This approach has been used in different genomic analysis [38], among them to differentiate between coding and non-coding DNA sequences in humans [39] or bacteria [40], to predict promotor regions [41] to characterize whole genomes in C. elegans and humans $[42,43]$, of protein families $[44,45]$, to allow the fast comparison of microbial genomes [46] or the study of the high order of the chromatin structure [43] .

\subsection{Mathematical analysis of the human genome highlights features of non-linear correlations in the Alu family of genomic parasites}

One likely possibility is that the non-linear nature of ATH could be due to a number of non-linear causes, and in Section 1 we discussed a number of ATH-related physical features in which disease progression was not directly proportional to the strength of the physical insult. On the other hand, we also hypothesized that evolution of ATH could be dependent on non-linear correlations in the structure of the human genome. The first report on the existence of these non-linear correlations in the human genome come from the work of Xiao et al, who used a chaos theory-derived nonlinear prediction method to differentiate among "random" and "non-random" (deterministic) DNA sequences [10]. In a first analysis, the authors studied the $\beta$-globin locus, which encodes six globin genes (with their exons and introns) and is enriched in Alu repeated sequences. They demonstrated that exonic and intronic sequences at the $\beta$-globin locus did not show significant deviation from randomness, while on the contrary most of the Alu sequences studied presented similar deterministic structures. This result suggested the existence of a structural determinants common to the different Alu elements. A further analysis showed that these non-linear correlations (deterministic structures) in the Alu elements were due to their dimeric composition, indicating that these could be based on the base-pairing of the two Alu-arms [10]. This intriguing result was somehow confirmed by further work by Moreno et al., which reported that the human genome 
displayed a multifractal behaviour, i.e. was rich in highly polymorphic sequences organized in a large number of combinations, which was strongly dependent in the content of Alu-S, the older and most abundant of the Alu families [49]. As already stated, Alu repeats have repeatedly colonized the human genome [11], but only a few Alu master genes remain transpositionally active [47]. Consequently, Alu elements are highly heterogeneous due to sequence divergences caused by the different evolutionary times in which they were retrotransposed into the genome, so that we can distinguish "old" Alus (classified in the Alu-J, Alu-S families) from "younger" Alus (Alu-Ya, Alu$\mathrm{Yb}$ families) by specific sequential features [48].

The nonlinear correlations reflected distinctive biological functions of Alu repeats due to their dimeric structure, which showed differences among old (Alu-J, Alu$\mathrm{S})$ and young (Alu-Ya, Alu-Yb) subfamilies. These differences were likely related to distinctive traits of their 3-dimensional folding, which were not present in other genomic regions [10]. In this sense, the secondary structure of Alu elements is very complex, being formed by two independent 7SL RNA-like folding units (components of the Signal recognition Particle, SRP) plus a domain of interaction between the two Alu arms $[48,50]$. These Alu sub-domains are sequentially and structurally heterogeneous due to sequence divergence [48], thus making the Alu family of sequences a potential generator of sequential and structural diversity.

In this context, in the next sections we will address the question of how highly heterogeneous Alu elements can impact on mechanisms regulating gene expression to facilitate ATH progression, and more specifically with those that could support a nonlinear developmental basis for this disease.

\section{4.- NEW NON-CODING RNA BIOMARKERS FOR ATHEROSCLEROSIS PROGRESSION}

4.1 ANRIL (Antisense №ncoding $\underline{R} N A$ in the INK4 $\underline{\text { Locus) }}$ : a long non-coding RNA at 9p21, the gene-desert locus which harbors the strongest risk factor for atherosclerosis

Coronary artery disease (CAD) has an important genetic background [51] and the increased susceptibility to CAD has been associated to a number of genetic variants [52]. Much interestingly, different genome-wide association studies (GWAS) have identified a strong association between the risk of coronary artery disease and a large 
intergenic locus at chromosome 9p21, spanning over $58 \mathrm{~kb}$ of DNA [53]. This genomic region includes several SNPs in tight linkage disequilibrium which disrupt predicted transcription factor binding sites involved in key physiological processes [54]. Much surprisingly, the 9p21 risk locus is a protein coding gene-free region, which otherwise encodes a long non-coding RNA (lncRNA) called ANRIL/CDKN2B-AS1 (ㅁntisense Noncoding $\underline{R} N A$ in the INK4 Locus or CDKN2B AntiSense 1), which has been identified as the strongest genetic factor associated to cardiovascular morbidity and mortality [55], also correlating with atherosclerosis severity [56]. At 9p21, ANRIL is found at the "far neighbourhood" (over $100 \mathrm{kbp}$ ) of the cyclin-dependent kinase inhibitor gene cluster p15/CDKN2B-p16/CDKN2A-p14/ARF, although the first exon of ANRIL is located next to the promoter of the p14/ARF gene and overlapped with two exons of $p 15 / C D K N 2 B$ [57], and to date no other transcript has been detected in this genomic region.

Long ncRNAs have been implicated in the regulation of most of the mechanisms of gene expression, either transcriptional, or postranscriptional (translational), as well as with the control of mRNA stability, pre-miRNA processing and chromatin structure [58], and consequently the mechanisms by which ANRIL would exert its effects are expected to be also many and diverse [59]. In this sense, it has been reported that in different diseases ANRIL behaves as a miRNA sponge by targeting miR-199a [60], miR-125a [61], miR-186 [62], or miR-323 [63] among others. Furthermore, ANRIL has been also described as a regulator of the signaling pathways ATM-E2F1 [64], VEGF [65], and NF-kB [66].

Another mechanism by which ANRIL would act is through the regulation of the cell cycle by interfering with the expression of the $p 15 / C D K N 2 B-p 16 / C D K N 2 A$ p14/ARF locus. In this sense it has been reported that ANRIL over-expression correlated with the down-regulation of p16(INK4a) [67], and p15(INK4b) [68] in different pathologies. Furthermore, ANRIL over-expression was shown to up-regulate a number of genes involved in the proliferation, adhesion and apoptosis in monocytes [56], while the depletion and mutagenesis of ANRIL reversed trans-regulation of these genes and normalized cellular functions [56]. 
A number of ANRIL splicing isoforms have been described [56] , and expression of these containing exons proximal to the INK4/ARF locus has been correlated with an increased risk of arteriosclerotic vascular disease [69,70]. ANRIL risk-alleles have been also associated with the inflammatory response, since these were shown to disrupt a binding site for the transcriptional factor STAT1 (Signal Transducers and Activators of Transcription-1) which mediated the transcriptional response to $\gamma$-IFN [71]. Furthermore, it has been also suggested that risk SNPs would alter the profile of ANRIL isoforms at the splicing level or by generating circular forms of ANRIL, which would impact on the expression of the neighbouring p15/CDKN2B-p16/CDKN2Ap14/ARF locus [72]. In this context, our group has reported that the ANRIL SNP rs10757278 (GG) doubled the risk for MACE in patients with CKD on haemodialysis through a yet unknown mechanism [73].

A recent report revealed an unsuspected functional relationship among ANRIL and members of the Alu family of repeated sequences, by which these last added a new regulatory tier to the ANRIL activity which impacted in the ability of cells to adhere and proliferate and facilitated atherosclerosis progression [56] (see Section 6 and Figure 2A).

\section{2- De-regulation of miRNA expression and atherosclerosis progression}

Like in many other complex diseases, multiple genes predispose to the vascular phenotype in ATH, and number of experimental models have highlighted a direct link between altered microRNA (miRNA) expression and the onset of ATH progression and cardiovascular disease [74-76]. MiRNAs, are a class of short ncRNAs (20-22 nucleotides long) that regulate the stability of most coding transcripts by binding to the 3'UTR of target mRNAs, hence playing a critical role in the coordination of different physiological and pathological processes. The interaction between miRNAs and mRNAs is highly complex and not completely understood [76]. Thus, miRNAs effects on individual genes can be modest, but have the potential to alter cellular responses via a coordinated effect on multiple targets. In addition, miRNA/ mRNA interaction may reflect a partial complementarities thus increasing the number of the off-target effects [77]. 
A number of serum miRNAs whose specific expression patterns could be associated to cancer, diabetes or cardiovascular diseases have been detected [78-79] making them potential biomarkers for disease detection. In this sense, there are sound evidences that miRNAs control vascular inflammation, with miR-21, miR-126, and miR-155 being reported as regulators of vessel remodeling [80], and miR-21and miR155 being involved in foam-cell formation [76,81]. Furthermore, a number or reports showed that lipid uptake by macrophages was regulated by miR-9, miR-125a-5p and miR-155 [82], while miR-33, miR-106, miR-122 and miR-144 controlled lipid homeostasis and miR-758 targeted transcripts involved in cholesterol metabolism and fatty acid oxidation [75]. On the other hand, miR-17-5p, miR-20a, miR-106a and miR424 have been shown to regulate monocyte/macrophage differentiation [80], and miR92a, the cluster miR-17-92 and let-7 were involved in angiogenesis [82]. Furthermore, it has been also established a functional link between hypoxia and the expression of a specific group of miRNAs [83], among them miR-125b, a multifunctional miRNA involved in the regulation of apoptosis, proliferation and maintenance of stem cell homeostasis [84]. Interestingly, mature miR-125b is transcribed from two different loci, miR-125b-1 at 11q24.1 and miR-125b-2 at 21q21.1 [85], and upregulation of miR-125b has been seen to increase the risk to coronary heart disease [86]. Expression of miR$125 \mathrm{~b}$ has been also related to the ATH process through its ability to down-regulate the expression of podocalyxin (PODXL), an adhesion molecule of endothelial cells [87]. In this context, we have recently described the up-regulation of miR-125b in an experimental model of atherosclerosis progression, as well as in human atherosclerotic plaques [88]. Those changes were reversed upon CD40 silencing [88].

\section{5.- GENOMIC Alu ELEMENTS IN SICKNESS AND IN HEALTH}

The structure of the human genome is highly complex. Protein-encoding regions represent only over $2 \%$ of the entire genome, and are immersed in a "dark matter" of non-coding sequences [89]. Formerly considered as "junk DNA", these regions include a number of transcribed non-coding RNAs as well as different mobile elements as endogenous retrovirus, DNA transposons and RNA-mediated retrotransposons, which have shaped the human genome along the evolution, and with many of them having specific roles in gene regulation [90]. The role of these mobile elements in transcriptional regulation is so important that the term mobilome has been coined to 
describe transposable elements involved in the coordination of gene expression as well as in the engineering of transcriptional networks [91].

As already stated, approx. one million of Alu elements have colonized the human genome by retrotransposition, mostly to gene-rich areas. This process of invasion, not only has had a major impact on the structure of the human genome in normal conditions (health), but also has shaped the genomic landscape for disease. A first consideration is that the retrotransposition process requires or would benefit of an "open" accessible chromatin structure to proceed, so that retrogressed elements would show a trend to concentrate in regulatory or gene rich regions. In this sense, a recent work by $\mathrm{Gu}$ et al, who used technologies based on chromosome conformation capture, showed that density of Alu elements correlated strongly and positively with functional DNA elements like enhancers and promoters [92]. Furthermore, there are also functional evidences of the integration of Alu elements in human genomic regulatory regions. Thus, and without being exhaustive (since this is not the aim of this review), a T-cell-specific enhancer, which contained an Alu element, was located in the last intron of the human CD8 alpha gene [93] while other repetitive Alu elements in its neighbourhood had the ability to form a cruciform structure that regulated the function of the CD8 alpha enhancer [94], and the human growth hormone (HGH) gene was shown to contain a functional silencer element within an Alu repeat in its 3'-flanking region [95]. This close involvement of Alu elements with regulatory regions has lead several authors to propose that retrogressed Alu repeats could be the source for new functional sites, as Pol II transcription factor binding sites, which would contribute to the generation of new regulatory networks [31], cryptic/alternative splice sites [96], or nuclear receptor binding sites [97], so that Alu elements could be considered as a large reservoir of potential regulatory functions which contributed to the evolution of the mechanisms regulating gene expression [29], or even of new functional genes [98].

On the other hand, Alu elements have been also related with the onset of a number of human diseases [30, 16] by different mechanisms: by causing genetic deletions and duplications [99], through insertional mutagenesis [100] or by contributing to the alteration of the methylation patterns of DNA [101]. In this sense, genomic regions highly enriched in Alu elements are considered as intrinsically unstable since these can be targeted by the homologous recombination machinery, due 
the high homology among Alu sequences to cause diseases [102]. Thus, to give a few examples, a retroinserted Alu element was shown to be causative of neurofibromatosis 1 (NF1) by inactivating a downstream exon during splicing and consequently shifting the reading frame of the NF1 gene [103], a deletion which occurred between two Alurepetitive sequences in the same orientation was shown to inactivate the low-density lipoprotein $(L D L)$ receptor gene in Korean patients suffering familial hypercholesterolemia (FH) [104] , and Alu-mediated recombinations (leading to exon skipping) were implicated in the origin of Hunter disease [105, 106].

\section{Alu ELEMENTS PLAY MULTIPLE ROLES IN THE PROGRESSION OF THE ATHEROSCLEROSIC DISEASE}

\subsection{ANRIL and Alu elements: two for tango.}

As stated above, ANRIL (ㅁntisense Noncoding $\underline{R} N A$ in the INK4 Locus) is a lncRNA-encoding genomic locus which harbours the strongest risk alele for atherosclerosis known to date [107]. Much interestingly, a recent work has highlighted a link among the regulation of ANRIL function and the presence of Alu elements [56]. In this work, authors first performed an expression analysis to characterize the pattern of ANRIL isoforms expressed in human PBMCs and in the monocyte cell line MonoMac, while subsequent analysis of ANRIL expression in CAD patients and controls demonstrated that ANRIL expression was significantly increased in those samples harbouring the risk allele. Much interestingly, ANRIL over-expression caused the upregulation of other mRNA transcripts related to cell adhesion, growth and proliferation, an effect that could be reversed by down-regulating ANRIL with a specific siRNA [56]. The mechanism by which ANRIL was able to regulate the expression of a number of genes in trans required the binding to ANRIL of Polycomb-group proteins PRC1/PRC2, CBX7, and SUZ12, among others, which were recruited to the promoters of their target genes upon ANRIL over-expression. Bioinformatic analysis of ANRIL and of the promoter regions of ANRIL-targeted genes highlighted the common presence of Alu elements in both suggesting that ANRIL might bind to chromatin through interaction via the Alu motif to guide PRC proteins to ANRIL-regulated genes to modify their expression. In this way, ANRIL over-expression would increase cell proliferation and adhesion and decrease apoptosis, thus modulating pro-atherogenic cell functions, 
while, on the contrary, ANRIL silencing reversed trans-regulation and normalized cellular functions [56] (Figure 2A).

On the other hand, the ANRIL murine ortologous is encoded in chromosome 4 [108] although the locus is not fully conserved between mice and human [109]. Interestingly, a murine mutant showing a $70 \mathrm{~kb}$ deletion of non-coding DNA at the Anril locus, which included the risk allele, showed a markedly decreased expression of $C d k n 2 a$ and $C d k a 2 b$, as well as an increased proliferation and diminished senescence of primary aortic smooth-muscle cells (SMCs) in culture [108], a fact strongly supporting the hypothesis that the ANRIL locus could be implicated with the pathogenesis of CAD. Nevertheless, the fact that mice do not have "bona fide" Alu elements [110] but the structurally related B1 elements (see [111], for a recent review), makes it difficult to determine the mechanism of action and compare it with that of the human ANRIL.

\section{2- Interaction of Alu-RNAs and miRNAs creates complex regulatory networks that are altered in disease}

As described above, many Alu elements in the human genome have functional RNA Pol III promoters (termed A/B boxes) in their 5' end which give them the ability to be transcribed autonomously and independently of the RNA Pol II transcriptional machinery $[12,26]$. Much interestingly, it has been recently described that Alu sequences can serve as promoters for RNA-Pol III- dependent (Pol II-independent) miRNA transcription [112], and over 50 miRNAs have been detected within Alu and other known repetitive elements [113]. In this sense, bioinformatic analysis has shown that $5 \%$ of intronic miRNA genes contained functional upstream Pol III-dependent Alu regulatory elements (A/B boxes) which would allow miRNA expression independently of the host gene (Pol II-dependent) transcription, thus explaining discordant expression between a miRNA and its host gene [114], although currently only a few Pol IIIdependent miRNAs have been functionally characterized [112].

On the other hand, there are several reports on the mutual functional interference between Alu elements and miRNAs resulting in the inactivation of one of these transcripts. Thus, almost 30 human miRNAs exhibited short-seed homology with highly conserved Alu sequence elements located at the 3' UTRs of human mRNAs, suggesting that these Alu sequences could serve as microRNA targets [115], and Daskalova et al. 
showed that the majority of the Alu sequences inserted in 3'UTRs of the human genes analyzed carried strong potential target sites for over 50 different miRNAs [116]. More recently, Di Ruocco et al., have shown that Alu RNA induced epithelial-tomesenchymal transition (EMT) in colorectal cancer cell lines by acting as a molecular sponge of miR-566 [117]. Furthermore, miR-15a-3p and miR-302d-3p, which are elevated in the stress response, were shown to target RAD1, GTSE1, NR2C1, FKBP9 and UBE2I exclusively within Alu elements [118], and targeting of Mdm2 and Mdm4 by miR-661, which causes their down-regulation with the subsequent augment of p53 activity and inhibition of cell cycle progression in p53-proficient cells, was shown to occur whithin Alu elements [119]. In this context, and although much more work has to be done on the interaction among Alu RNAs and miRNAs, it is currently accepted that individual Alu RNAs could behave as molecular sponges for miRNAs involved in atherosclerosis progression and impact in disease development (Figure 2B).

\subsection{Alu elements are common binding sites for transcription factors such as NF- $\kappa b$ and may impact on gene expression of the inflammatory response.}

NF- $\kappa \mathrm{B}$ proteins are critical regulators of the immune response with a substantiated role in ATH progression in animal models of ASVD [120] and in human ASVD [121, 122] patients. Activated NF- $\kappa$ B has been localized in vascular endothelial cells (VEC), smooth muscle cells (SMCs) and lymphocytes in the vasa-vasorum of abdominal aortas with atherosclerotic plaques from deceased patients [122]. NF- $\kappa \mathrm{B}$ can be activated through two different, canonical and non-canonical, pathways. In the canonical pathway, NF-кB nuclear factors (RelA or p65, RelB, c-Rel, p50 and p52) are maintained inactive in the cytoplasm by interacting with $\mathrm{I} \kappa \mathrm{B}$ inhibitory proteins. Receptor triggering (PRRs, TNFRs, TCR, BCR, etc.), activates IKKs which cause IкB phosphorylation and their subsequent proteasomal degradation, thus facilitating the

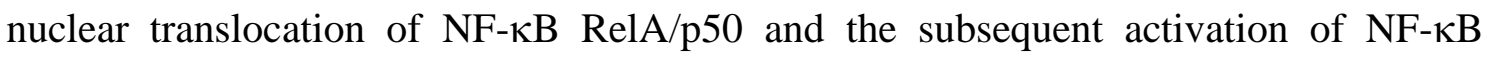
downstream target genes [123]. In the alternative, non-canonical NF- $\kappa B$ pathway, NIK

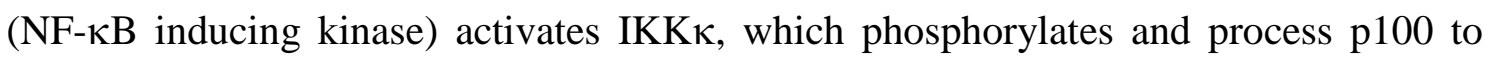
p52, inducing the formation of a transcriptionally active RelB/p52-complex [123]. In this context, we have recently described, the up-regulation of the activator $I K K \kappa$ and the down-regulation of the $I K B \alpha$ inhibitor during disease progression in the 


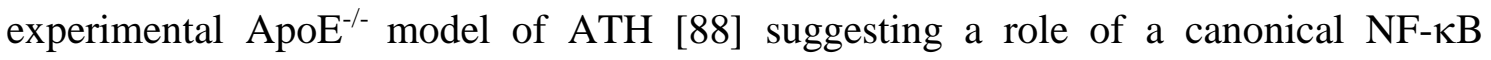
activation in ATH progression.

NF- $\kappa \mathrm{B}$ nuclear factors (RelA, RelB, c-Rel) bind to the consensus $\kappa \mathrm{B}$ site (5'GGGRNYYYCC-3') in the promoters or enhancers of target genes [123]. Much interestingly, NF-אB has been shown to also bind to many non-consensus sites [124] of which near $10 \%$ have been detected in Alu-repetitive elements (termed Alu- $\kappa \mathrm{B}$ elements) [125]. Although, only a few of them have been directly correlated with changes in the expression of the associated genes, it has been suggested that these Alu$\kappa \mathrm{B}$ elements could perform other cell type-specific functions, as sequestering transcriptionally inert NF- $\mathrm{\kappa B}$ molecules to allow competent factors to activate target genes but preventing excessive targeting and superactivation of promoters [125].This data suggest that Alu elements combined with other nearby cis-acting elements might play an important role in expanding the repertoire of NF- $\kappa \mathrm{B}$ binding sites to engage new genes into NF-кB-dependent regulatory networks (Figure 2C). Furthermore, genomewide Chip.seq in different individuals and cell lines has demonstrated that binding NF$\kappa \mathrm{B}$ sites are polymorphic and can differ by over 7.5\% among individuals. Most of these differences were in SNPs in intergenic regions and correlated with differences in gene expression, indicating that polymorphic variation in binding sites could have functional consequences [126]. Although no data is available on how much of that binding variation occurs in Alu elements, it could be expected that significant differences in transcription factor binding sites as well as in gene expression between individuals could be due to polymorphic Alu repeats.

\subsection{A polymorphic Alu insertion controls the renin-angiotensin system}

It is known that elevated levels of angiotensin II (Ang II) contribute to vascular disease, and that kidney plays a critical role in the regulation of the Renin-AngiotensinAldosterone $\underline{\text { System }(R A A S) ~[127] . ~ K i d n e y ~ r e n i n ~ i s ~ r e l e a s e d ~ i n t o ~ b l o o d ~ w h e r e ~ i t ~ c l e a v e s ~}$ circulating angiotensinogen into angiotensin I, which is subsequently transformed in Ang II by the angiotensin converting enzyme (ACE) produced in the vascular endothelium. Ang II may accelerate ATH through activation of factors such as NF- $\mathrm{B}$, adhesion molecules, TGF- $\beta$ or endothelin-1, thereby inducing vascular growth, cell migration and inflammation [128]. In addition, Ang II is a potent stimulus for pro- 
oxidant enzymes leading to an increase in reactive oxygen species (ROS) production, and consequently increased oxidative stress. On the contrary, blocking RAAS has demonstrated beneficial effects for the treatment of cardiovascular and renal disease [129].

Alu elements are involved in the regulation of RAAS, and consequently in the progress of renal [130] and cardiovascular diseases [131], by virtue of a polymeric Alu insertion in the intron 16 of the ACE gene which gives rise to two different alleles: the "insertion allele" (I allele) and the "deletion allele" (D allele). The insertion of the Alu element (I allele) in the ACE gene resulted in an ORF shift which caused the premature termination of the ACE protein and originated a protein with a single active site in the N-terminal domain [29]. Homozygous D/D individuals have plasma ACE levels about twice as high as those homozygous I/I individuals [132], and diminished levels of tissue ACE [133]. Surprisingly, the Alu repeat was found to also upregulate the transcriptional activity of ACE promoter [134]. However, association studies on the I/D polymorphisms of ACE gene and cardiovascular outcomes are still controversial due to the lack of powered studies and the existence of interactions with other genes or environmental factors [135].

\section{CONCLUDING REMARKS AND FUTURE TRENDS}

CKD-dependent atherosclerosis is a very complex disease whose development requires the functional integration of a number of gene networks in different organs and tissues. Although great efforts have been devised to explore the landscape of molecular alterations which underlie the development of ATH, and despite the wealth of knowledge generated, we still have a limited vision of most of the mechanisms involved in ATH development, their interactions or their mutual interferences. Clearly, new approaches for ATH research are required to integrate new tiers of information and new regulatory layers. In this sense, chaos theory and the study of non-linear dynamic systems offers new conceptual approaches and insights to better understand highly complex problems [136]. Chaotic systems, which can be defined as deterministic but not predictable, are characterized by their exquisite sensitivity to their initial conditions which will develop by following the trajectories of strange attractors of fractal nature [137]. A number of authors have proposed a chaotic component for the development of 
atherosclerosis [138-140], hypothesis that has been confirmed by work by Xiao et al, who used a chaos theory-derived nonlinear prediction method to highlight deterministic (non-random) structures in the repetitive Alu elements caused by their dimeric composition, a likely basis for a non-linear regulatory behaviour [10]. These results were further backed by Moreno et al., who used a multifractal approach to study the human genome, showing that multifractality was strongly correlated with the presence of repeated elements of the Alu family [49]. These works made conceptual links among disease (ATH), the overall structure of the human genome, and focused our attention in the functional involvement of the repeated elements of the Alu family in ATH progression. In conclusion, the advent of the genomic revolution has highlighted the involvement of non-coding DNAs and RNAs in human diseases. Here we have reviewed data on the role of two of these, the IncRNA ANRIL and the family of Alu repeated elements on ATH onset and progression. Although much work remains to be done on these (and other) non-coding elements, it is becoming clear that the natural history of human disease is no longer a question of proteins and coding genomic regions, and that non-coding regions do have an important role in disease development. 


\section{DECLARATIONS:}

\section{ETHICS APPROVAL AND CONSENT TO PARTICIPATE}

Not applicable.

\section{CONSENT FOR PUBLICATION}

Not applicable.

\section{AVAILABILITY OF DATA AND MATERIALS}

Please contact author for data requests.

\section{COMPETING INTERESTS}

The authors declare that they have no competing interests

\section{FUNDING}

Not applicable

\section{AUTHORS' CONTRIBUTIONS}

The contribution of each authors were as follows: MH conceived and drafted the manuscript, EN conceived and drafted the manuscript, JC provided intellectual content of critical importance to the work, and JT helped to draft the manuscript. All authors read and approved the final manuscript.

\section{ACKNOWLEDGEMENTS}

We acknowledge to our colleagues at the ND-HUB for discussions on the topic, inputs and comments on the manuscript. We apologize to all colleagues whose work hasn't been cited because of space constraints. 


\section{REFERENCES}

1. Louridas, G.E.; Lourida, K.G. Systems biology and biomechanical model of heart failure. Curr Cardiol Rev 2012, 8, 220-230. DOI: 10.2174/157340312803217238.

2. Recordati, G.; Bellini, T.G. A definition of internal constancy and homeostasis in the context of non-equilibrium thermodynamics. Exp Physiol 2004, 89, 27-38._DOI: 10.1113/expphysiol.2003.002633

3. Goldberger, A.L. Non-linear dynamics for clinicians: chaos theory, fractals, and complexity at the bedside. Lancet 1996, 347, 1312-1314. DOI:10.1016/S01406736(96)90948-4.

4. Bruschke, A. V. and Kramer, J. R. and Bal, E. T. and Haque, I. U. and Detrano, R. C. and Goormastic, M. The dynamics of progression of coronary atherosclerosis studied in 168 medically treated patients who underwent coronary arteriography three times. Am Heart J 1989 117, 296-305. https://www.ncbi.nlm.nih.gov/pubmed/2916405.

5. Veress, A. I.; Vince, D. G.; Anderson, P. M.; Cornhill, J. F.; Herderick, E. E.; Klingensmith, J. D.; Kuban, B. D.; Greenberg, N. L.; Thomas, J. D., Vascular mechanics of the coronary artery. $Z$ Kardiol 2000, 89 Suppl 2, 92-100. https://www.ncbi.nlm.nih.gov/pubmed/10769410 >.

6. Kamenskiy, A. V.; Dzenis, Y. A.; MacTaggart, J. N.; Lynch, T. G.; Jaffar Kazmi, S.A.; Pipinos, I. I., Nonlinear mechanical behavior of the human common, external, and internal carotid arteries in vivo. J Surg Res 2012, 176 (1), 329-36. https://www.ncbi.nlm.nih.gov/pubmed/22099586.

7. Liu, Q.; Han, H. C., Mechanical buckling of artery under pulsatile pressure. $J$ Biomech 2012, 45 (7), 1192-8. https://www.ncbi.nlm.nih.gov/pubmed/22356844 .

8. Li, Z. Y.; Gillard, J. H., Simulation of the interaction between blood flow and atherosclerotic plaque. Conf Proc IEEE Eng Med Biol Soc 2007, 2007, 1699-702. https://www.ncbi.nlm.nih.gov/pubmed/18002302.

9. Nguyen, C. M.; Levy, A. J., The mechanics of atherosclerotic plaque rupture by inclusion/matrix interfacial decohesion. $J$ Biomech 2010, 43 (14), 2702-8. https://www.ncbi.nlm.nih.gov/pubmed/20723900.

10. Xiao, Y.; Huang, Y.; Li, M.; Xu, R.; Xiao, S., Nonlinear analysis of correlations in Alu repeat sequences in DNA. Phys Rev E Stat Nonlin Soft Matter Phys 2003, 68 (6 Pt 1), 061913. https://www.ncbi.nlm.nih.gov/pubmed/14754240. 
11. Häsler, J.; Samuelsson, T.; Strub, K., Useful 'junk': Alu RNAs in the human transcriptome. Cell Mol Life Sci 2007, 64 (14), 1793-800. https://www.ncbi.nlm.nih.gov/pubmed/17514354.

12. Chen, L. L.; Yang, L., ALUternative Regulation for Gene Expression. Trends Cell Biol 2017, 27 (7), 480-490. https://www.ncbi.nlm.nih.gov/pubmed/28209295.

13. Conti, A.; Carnevali, D.; Bollati, V.; Fustinoni, S.; Pellegrini, M.; Dieci, G., Identification of RNA polymerase III-transcribed Alu loci by computational screening of RNA-Seq data. Nucleic Acids Res 2015, 43 (2), 817-35. https://www.ncbi.nlm.nih.gov/pubmed/25550429.

14. Lazaros, L.; Kitsou, C.; Kostoulas, C.; Bellou, S.; Hatzi, E.; Ladias, P.; Stefos, T.; Markoula, S.; Galani, V.; Vartholomatos, G.; Tzavaras, T.; Georgiou, I., Retrotransposon expression and incorporation of cloned human and mouse retroelements in human spermatozoa. Fertil Steril 2017, 107 (3), 821-830. https://www.ncbi.nlm.nih.gov/pubmed/28139237.

15. Navarro, E.; Espinosa, L.; Adell, T.; Torà, M.; Berrozpe, G.; Real, F. X., Expressed sequence tag (EST) phenotyping of HT-29 cells: cloning of ser/thr protein kinase EMK1, kinesin KIF3B, and of transcripts that include Alu repeated elements. Biochim Biophys Acta 1999, $1450 \quad$ (3), 254-64. https://www.ncbi.nlm.nih.gov/pubmed/10395937.

16. Kim, S.; Cho, C. S.; Han, K.; Lee, J., Structural Variation of Alu Element and Human Disease. Genomics Inform 2016, $14 \quad$ (3), 70-77. https://www.ncbi.nlm.nih.gov/pubmed/27729835.

17. Chopra-Tandon, N.; Wu, H.; Arcaro, K. F.; Sturgeon, S. R., Relationships between Global DNA Methylation in Circulating White Blood Cells and Breast Cancer Risk Factors. J Cancer Epidemiol 2017, 2017, 2705860. https://www.ncbi.nlm.nih.gov/pubmed/28484492.

18. Derrien, T.; Johnson, R.; Bussotti, G.; Tanzer, A.; Djebali, S.; Tilgner, H.; Guernec, G.; Martin, D.; Merkel, A.; Knowles, D. G.; Lagarde, J.; Veeravalli, L.; Ruan, X.; Ruan, Y.; Lassmann, T.; Carninci, P.; Brown, J. B.; Lipovich, L.; Gonzalez, J. M.; Thomas, M.; Davis, C. A.; Shiekhattar, R.; Gingeras, T. R.; Hubbard, T. J.; Notredame, C.; Harrow, J.; Guigó, R., The GENCODE v7 catalog of human long noncoding RNAs: analysis of their gene structure, evolution, and expression. Genome $\quad$ Res 22 2012, $22 \quad$ (9), $\quad$ 1775-89. https://www.ncbi.nlm.nih.gov/pubmed/22955988. 
19. Schmid, C. W.; Jelinek, W. R., The Alu family of dispersed repetitive sequences. $\begin{array}{llll}\text { Science } & \mathbf{1 9 8 2}, & 216 & \text { (4550), }\end{array}$ https://www.ncbi.nlm.nih.gov/pubmed/6281889.

20. Daniel, C.; Behm, M.; Öhman, M., The role of Alu elements in the cis-regulation of RNA processing. Cell Mol Life Sci 2015, 72 (21), 4063-76. https://www.ncbi.nlm.nih.gov/pubmed/26223268.

21. Batzer, M. A.; Deininger, P. L.; Hellmann-Blumberg, U.; Jurka, J.; Labuda, D.; Rubin, C. M.; Schmid, C. W.; Zietkiewicz, E.; Zuckerkandl, E., Standardized nomenclature for Alu repeats. $J$ Mol Evol 1996, 42 (1), 3-6. https://www.ncbi.nlm.nih.gov/pubmed/8576960.

22. Mighell, A. J.; Markham, A. F.; Robinson, P. A., Alu sequences. FEBS Lett 1997, 417 (1), 1-5. https://www.ncbi.nlm.nih.gov/pubmed/9395063.

23. Wallace, N.; Wagstaff, B. J.; Deininger, P. L.; Roy-Engel, A. M., LINE-1 ORF1 protein enhances Alu SINE retrotransposition. Gene 2008, 419 (1-2), 1-6. https://www.ncbi.nlm.nih.gov/pubmed/18534786.

24. Cordaux, R.; Batzer, M. A., The impact of retrotransposons on human genome evolution. Nat Rev Genet 2009, $10 \quad$ (10), 691-703. https://www.ncbi.nlm.nih.gov/pubmed/19763152.

25. Zhang, L.; Chen, J. G.; Zhao, Q., Regulatory roles of Alu transcript on gene expression. Exp Cell Res 2015, $338 \quad$ (1), 113-8. https://www.ncbi.nlm.nih.gov/pubmed/26210645.

26. Ichiyanagi, K., Regulating Pol III transcription to change Pol II transcriptome. Cell Cycle 2014, 13 (23), 3625-6. https://www.ncbi.nlm.nih.gov/pubmed/25551358.

27. Moolhuijzen, P.; Kulski, J. K.; Dunn, D. S.; Schibeci, D.; Barrero, R.; Gojobori, T.; Bellgard, M., The transcript repeat element: the human Alu sequence as a component of gene networks influencing cancer. Funct Integr Genomics 2010, 10 (3), 307-19. https://www.ncbi.nlm.nih.gov/pubmed/20393868.

28. Sela, N.; Mersch, B.; Gal-Mark, N.; Lev-Maor, G.; Hotz-Wagenblatt, A.; Ast, G., Comparative analysis of transposed element insertion within human and mouse genomes reveals Alu's unique role in shaping the human transcriptome. Genome Biol 2007, 8 (6), R127. https://www.ncbi.nlm.nih.gov/pubmed/17594509.

29. Häsler, J.; Strub, K., Alu elements as regulators of gene expression. Nucleic Acids Res 2006, 34 (19), 5491-7. https://www.ncbi.nlm.nih.gov/pubmed/17020921. 
30. Chenais, B., Transposable elements in cancer and other human diseases. Curr Cancer Drug Targets 2015, $15 \quad$ (3), 227-42. https://www.ncbi.nlm.nih.gov/pubmed/25808076.

31. Pandey, R.; Mukerji, M., From 'JUNK' to just unexplored noncoding knowledge: the case of transcribed Alus. Brief Funct Genomics 2011, 10 (5), 294-311. https://www.ncbi.nlm.nih.gov/pubmed/21987713.

32. Jeffrey, H. J., Chaos game representation of gene structure. Nucleic Acids Res 1990, 18 (8), 2163-70. https://www.ncbi.nlm.nih.gov/pubmed/2336393

33. Arakawa, K.; Oshita, K.; Tomita, M., A web server for interactive and zoomable Chaos Game Representation images. Source Code Biol Med 2009, 4, 6. https://www.ncbi.nlm.nih.gov/pubmed/19761591

34. Almeida, J. S., Sequence analysis by iterated maps, a review. Brief Bioinform 2014, 15 (3), 369-75. https://www.ncbi.nlm.nih.gov/pubmed/24162172

35. Oliver, J. L.; Bernaola-Galván, P.; Guerrero-García, J.; Román-Roldán, R., Entropic profiles of DNA sequences through chaos-game-derived images. J Theor Biol 1993, 160 (4), 457-70. https://www.ncbi.nlm.nih.gov/pubmed/8501918

36. Messaoudi, I.; Elloumi-Oueslati, A.; Lachiri, Z., Building Specific Signals from Frequency Chaos Game and Revealing Periodicities Using a Smoothed Fourier Analysis. IEEE/ACM Trans Comput Biol Bioinform 2014, 11 (5), 863-77. https://www.ncbi.nlm.nih.gov/pubmed/26356859

37. Joseph, J.; Sasikumar, R., Chaos game representation for comparison of whole $\begin{array}{lllll}\text { genomes. } & B M C & \text { Bioinformatics } & \text { 2006, } & 7,\end{array}$ https://www.ncbi.nlm.nih.gov/pubmed/16677374

38. Fu, W.; Wang, Y.; Lu, D., Multifractal Analysis of Genomic Sequences CGR Images. Conf Proc IEEE Eng Med Biol Soc 2005, 5, 4783-6. https://www.ncbi.nlm.nih.gov/pubmed/17281311

39. Provata, A.; Oikonomou, T., Power law exponents characterizing human DNA. Phys Rev E Stat Nonlin Soft Matter Phys 2007, 75 (5 Pt 2), 056102. https://www.ncbi.nlm.nih.gov/pubmed/17677128

40. Stan, C.; Cristescu, M. T.; Luiza, B. I.; Cristescu, C. P., Investigation on series of length of coding and non-coding DNA sequences of bacteria using multifractal 
detrended cross-correlation analysis. $J$ Theor Biol 2013, 321, 54-62. https://www.ncbi.nlm.nih.gov/pubmed/23313335

41. Yang, J. Y.; Zhou, Y.; Yu, Z. G.; Anh, V.; Zhou, L. Q., Human Pol II promoter recognition based on primary sequences and free energy of dinucleotides. BMC Bioinformatics 2008, 9, 113. https://www.ncbi.nlm.nih.gov/pubmed/18294399

42. Vélez, P. E.; Garreta, L. E.; Martínez, E.; Díaz, N.; Amador, S.; Tischer, I.; Gutiérrez, J. M.; Moreno, P. A., The Caenorhabditis elegans genome: a multifractal analysis. Genet Mol Res 2010, $9 \quad$ (2), 949-65. https://www.ncbi.nlm.nih.gov/pubmed/20506082

43. Audit, B.; Vaillant, C.; Arnéodo, A.; d'Aubenton-Carafa, Y.; Thermes, C., Wavelet Analysis of DNA Bending Profiles reveals Structural Constraints on the Evolution of Genomic Sequences. J Biol Phys 2004, $30 \quad$ (1), 33-81. https://www.ncbi.nlm.nih.gov/pubmed/23345861

44. Yu, Z. G.; Anh, V.; Lau, K. S., Multifractal and correlation analyses of protein sequences from complete genomes. Phys Rev E Stat Nonlin Soft Matter Phys 2003, 68 (2 Pt 1), 021913. https://www.ncbi.nlm.nih.gov/pubmed/14525012

45. Nie, G.; Li, Y.; Wang, F.; Wang, S.; Hu, X., A novel fractal approach for predicting G-protein-coupled receptors and their subfamilies with support vector machines. Biomed Mater Eng 2015, $26 \quad$ Suppl 1, S1829-36. https://www.ncbi.nlm.nih.gov/pubmed/26405954

46. Swain,T., Fast comparison of microbial genomes using the chaos game representation for metagenomic applications. Procedia Computer Science 2013, 18, 1372-1380. DOI: 10.1016/j.procs.2013.05.304

47. Kim, Y. J.; Lee, J.; Han, K., Transposable Elements: No More 'Junk DNA'. $\begin{array}{lllll}\text { Genomics } & \text { Inform } & \mathbf{2 0 1 2}, & 10 & \text { (4), }\end{array}$ https://www.ncbi.nlm.nih.gov/pubmed/23346034

48. Labuda, D.; Striker, G., Sequence conservation in Alu evolution. Nucleic Acids Res 1989, 17 (7), 2477-91. https://www.ncbi.nlm.nih.gov/pubmed/2541408

49. Moreno, P. A.; Vélez, P. E.; Martínez, E.; Garreta, L. E.; Díaz, N.; Amador, S.; Tischer, I.; Gutiérrez, J. M.; Naik, A. K.; Tobar, F.; García, F., The human genome: a multifractal analysis. BMC Genomics 2011, 12, 506. https://www.ncbi.nlm.nih.gov/pubmed/21999602

50. Sinnett, D.; Richer, C.; Deragon, J. M.; Labuda, D., Alu RNA secondary structure 
consists of two independent 7 SL RNA-like folding units. J Biol Chem 1991, 266 (14), 8675-8. < https://www.ncbi.nlm.nih.gov/pubmed/1709156

51. McPherson, R.; Tybjaerg-Hansen, A., Genetics of Coronary Artery Disease. Circ Res 2016, 118 (4), 564-78. https://www.ncbi.nlm.nih.gov/pubmed/26892958

52. Lloyd-Jones, D. M.; Nam, B. H.; D'Agostino, R. B.; Levy, D.; Murabito, J. M.; Wang, T. J.; Wilson, P. W.; O'Donnell, C. J., Parental cardiovascular disease as a risk factor for cardiovascular disease in middle-aged adults: a prospective study of parents and offspring. JAMA 2004, 291 (18), 2204-11. https://www.ncbi.nlm.nih.gov/pubmed/15138242

53. McPherson, R.; Pertsemlidis, A.; Kavaslar, N.; Stewart, A.; Roberts, R.; Cox, D. R.; Hinds, D. A.; Pennacchio, L. A.; Tybjaerg-Hansen, A.; Folsom, A. R.; Boerwinkle, E.; Hobbs, H. H.; Cohen, J. C., A common allele on chromosome 9 associated with coronary heart disease. Science 2007, 316 (5830), 1488-91. https://www.ncbi.nlm.nih.gov/pubmed/17478681

54. Harismendy, O.; Notani, D.; Song, X.; Rahim, N. G.; Tanasa, B.; Heintzman, N.; Ren, B.; Fu, X. D.; Topol, E. J.; Rosenfeld, M. G.; Frazer, K. A., 9p21 DNA variants associated with coronary artery disease impair interferon- $\gamma$ signalling response. $\quad$ Nature $\quad$ 2011, $470 \quad$ (7333), https://www.ncbi.nlm.nih.gov/pubmed/21307941

55. Helgadottir, A.; Thorleifsson, G.; Manolescu, A.; Gretarsdottir, S.; Blondal, T.; Jonasdottir, A.; Sigurdsson, A.; Baker, A.; Palsson, A.; Masson, G.; Gudbjartsson, D. F.; Magnusson, K. P.; Andersen, K.; Levey, A. I.; Backman, V. M.; Matthiasdottir, S.; Jonsdottir, T.; Palsson, S.; Einarsdottir, H.; Gunnarsdottir, S.; Gylfason, A.; Vaccarino, V.; Hooper, W. C.; Reilly, M. P.; Granger, C. B.; Austin, H.; Rader, D. J.; Shah, S. H.; Quyyumi, A. A.; Gulcher, J. R.; Thorgeirsson, G.; Thorsteinsdottir, U.; Kong, A.; Stefansson, K., A common variant on chromosome 9p21 affects the risk of myocardial infarction. Science 2007, 316 (5830), 1491-3. https://www.ncbi.nlm.nih.gov/pubmed/17478679

56. Holdt, L. M.; Hoffmann, S.; Sass, K.; Langenberger, D.; Scholz, M.; Krohn, K.; Finstermeier, K.; Stahringer, A.; Wilfert, W.; Beutner, F.; Gielen, S.; Schuler, G.; Gäbel, G.; Bergert, H.; Bechmann, I.; Stadler, P. F.; Thiery, J.; Teupser, D., Alu elements in ANRIL non-coding RNA at chromosome 9p21 modulate atherogenic cell functions through trans-regulation of gene networks. PLoS Genet 2013, 9 (7), e1003588. https://www.ncbi.nlm.nih.gov/pubmed/23861667

57. Pasmant, E.; Laurendeau, I.; Héron, D.; Vidaud, M.; Vidaud, D.; Bièche, I., Characterization of a germ-line deletion, including the entire INK4/ARF locus, in a 
melanoma-neural system tumor family: identification of ANRIL, an antisense noncoding RNA whose expression coclusters with ARF. Cancer Res 2007, 67 (8), 3963-9. https://www.ncbi.nlm.nih.gov/pubmed/17440112

58. Bunch, H., Gene regulation of mammalian long non-coding RNA. Mol Genet Genomics 2017. DOI: 10.1007/s00438-017-1370-9

59. Aguilo, F.; Di Cecilia, S.; Walsh, M. J., Long Non-coding RNA ANRIL and Polycomb in Human Cancers and Cardiovascular Disease. Curr Top Microbiol Immunol 2016, 394, 29-39. https://www.ncbi.nlm.nih.gov/pubmed/26220772

60. Xu, S. T.; Xu, J. H.; Zheng, Z. R.; Zhao, Q. Q.; Zeng, X. S.; Cheng, S. X.; Liang, Y. $\mathrm{H}$;; Hu, Q. F., Long non-coding RNA ANRIL promotes carcinogenesis via sponging miR-199a in triple-negative breast cancer. Biomed Pharmacother 2017, 96, 14-21. https://www.ncbi.nlm.nih.gov/pubmed/28961506

61. Li, R.; Yin, F.; Guo, Y. Y.; Zhao, K. C.; Ruan, Q.; Qi, Y. M., Knockdown of ANRIL aggravates $\mathrm{H} 2 \mathrm{O} 2$-induced injury in PC-12 cells by targeting microRNA125a. Biomed Pharmacother 2017, 92, 952-961. https://www.ncbi.nlm.nih.gov/pubmed/28609843

62. Zhang, J. J.; Wang, D. D.; Du, C. X.; Wang, Y., Long Noncoding RNA ANRIL Promotes Cervical Cancer Development By Acting as a Sponge of miR-186. Oncol Res 2017. DOI: 10.3727/096504017X14953948675449

63. Zhang, H.; Wang, X.; Chen, X., Potential Role of Long Non-Coding RNA ANRIL in Pediatric Medulloblastoma Through Promotion on Proliferation and Migration by Targeting miR-323. J Cell Biochem 2017, 118 (12), 4735-4744. doi: $10.1002 /$ jcb. 26141

64. Chen, S.; Zhang, J. Q.; Chen, J. Z.; Chen, H. X.; Qiu, F. N.; Yan, M. L.; Chen, Y. L.; Peng, C. H.; Tian, Y. F.; Wang, Y. D., The over expression of long non-coding RNA ANRIL promotes epithelial-mesenchymal transition by activating the ATME2F1 signaling pathway in pancreatic cancer: An in vivo and in vitro study. Int $J$ Biol Macromol 2017, 102, 718-728. https://www.ncbi.nlm.nih.gov/pubmed/28344092

65. Thomas, A. A.; Feng, B.; Chakrabarti, S., ANRIL: A Regulator of VEGF in Diabetic Retinopathy. Invest Ophthalmol Vis Sci 2017, 58 (1), 470-480. https://www.ncbi.nlm.nih.gov/pubmed/28122089

66. Zhang, D.; Sun, G.; Zhang, H.; Tian, J.; Li, Y., Long non-coding RNA ANRIL indicates a poor prognosis of cervical cancer and promotes carcinogenesis via 
PI3K/Akt pathways. Biomed Pharmacother 2017, 85, 511-516. https://www.ncbi.nlm.nih.gov/pubmed/27899255

67. Royds, J. A.; Pilbrow, A. P.; Ahn, A.; Morrin, H. R.; Frampton, C.; Russell, I. A.; Moravec, C. S.; Sweet, W. E.; Tang, W. H.; Currie, M. J.; Hung, N. A.; Slatter, T. L., The rs11515 Polymorphism Is More Frequent and Associated With Aggressive Breast Tumors with Increased ANRIL and Decreased p16 (INK4a) Expression. Front Oncol 2015, 5, 306. https://www.ncbi.nlm.nih.gov/pubmed/26835415

68. Chen, D.; Zhang, Z.; Mao, C.; Zhou, Y.; Yu, L.; Yin, Y.; Wu, S.; Mou, X.; Zhu, Y., ANRIL inhibits p15(INK4b) through the TGF $\beta 1$ signaling pathway in human esophageal squamous cell carcinoma. Cell Immunol 2014, 289 (1-2), 91-6. https://www.ncbi.nlm.nih.gov/pubmed/24747824

69. Burd, C. E.; Jeck, W. R.; Liu, Y.; Sanoff, H. K.; Wang, Z.; Sharpless, N. E., Expression of linear and novel circular forms of an INK4/ARF-associated noncoding RNA correlates with atherosclerosis risk. PLoS Genet 2010, 6 (12), e1001233. https://www.ncbi.nlm.nih.gov/pubmed/21151960

70. Assimes, T. L.; Knowles, J. W.; Basu, A.; Iribarren, C.; Southwick, A.; Tang, H.; Absher, D.; Li, J.; Fair, J. M.; Rubin, G. D.; Sidney, S.; Fortmann, S. P.; Go, A. S.; Hlatky, M. A.; Myers, R. M.; Risch, N.; Quertermous, T., Susceptibility locus for clinical and subclinical coronary artery disease at chromosome 9p21 in the multiethnic ADVANCE study. Hum Mol Genet 2008, 17 (15), 2320-8. https://www.ncbi.nlm.nih.gov/pubmed/18443000

71. McLaren, J. E.; Ramji, D. P., Interferon gamma: a master regulator of atherosclerosis. Cytokine Growth Factor Rev 2009, 20 (2), 125-35. https://www.ncbi.nlm.nih.gov/pubmed/19041276

72. Hannou, S. A.; Wouters, K.; Paumelle, R.; Staels, B., Functional genomics of the CDKN2A/B locus in cardiovascular and metabolic disease: what have we learned from GWASs? Trends Endocrinol Metab 2015, 26 (4), 176-84. https://www.ncbi.nlm.nih.gov/pubmed/25744911

73. Arbiol-Roca, A.; Padró-Miquel, A.; Hueso, M.; Navarro, E.; Alía-Ramos, P.; González-Álvarez, M. T.; Rama, I.; Torras, J.; Grinyó, J. M.; Cruzado, J. M.; Lloberas, N., Association of ANRIL gene polymorphisms with major adverse cardiovascular events in hemodialysis patients. Clin Chim Acta 2017, 466, 61-67. https://www.ncbi.nlm.nih.gov/pubmed/28057453

74. Andreou, I.; Sun, X.; Stone, P. H.; Edelman, E. R.; Feinberg, M. W., miRNAs in atherosclerotic plaque initiation, progression, and rupture. Trends Mol Med 2015, 21 
(5), 307-18. https://www.ncbi.nlm.nih.gov/pubmed/25771097

75. Aryal, B.; Rotllan, N.; Fernández-Hernando, C., Noncoding RNAs and atherosclerosis. Curr Atheroscler Rep 2014, $16 \quad$ (5), 407. https://www.ncbi.nlm.nih.gov/pubmed/24623179

76. Feinberg, M. W.; Moore, K. J., MicroRNA Regulation of Atherosclerosis. Circ Res 2016, 118 (4), 703-20. https://www.ncbi.nlm.nih.gov/pubmed/26892968

77. Singh, S.; Narang, A. S.; Mahato, R. I., Subcellular fate and off-target effects of siRNA, shRNA, and miRNA. Pharm Res 2011, 28 (12), 2996-3015. https://www.ncbi.nlm.nih.gov/pubmed/22033880

78. Chen, X.; Ba, Y.; Ma, L.; Cai, X.; Yin, Y.; Wang, K.; Guo, J.; Zhang, Y.; Chen, J.; Guo, X.; Li, Q.; Li, X.; Wang, W.; Wang, J.; Jiang, X.; Xiang, Y.; Xu, C.; Zheng, P.; Zhang, J.; Li, R.; Zhang, H.; Shang, X.; Gong, T.; Ning, G.; Zen, K.; Zhang, C. Y., Characterization of microRNAs in serum: a novel class of biomarkers for diagnosis of cancer and other diseases. Cell Res 2008, 18 (10), 997-1006. https://www.ncbi.nlm.nih.gov/pubmed/18766170

79. Diehl, P.; Fricke, A.; Sander, L.; Stamm, J.; Bassler, N.; Htun, N.; Ziemann, M.; Helbing, T.; El-Osta, A.; Jowett, J. B.; Peter, K., Microparticles: major transport vehicles for distinct microRNAs in circulation. Cardiovasc Res 2012, 93 (4), 63344. https://www.ncbi.nlm.nih.gov/pubmed/22258631

80. Urbich, C.; Kuehbacher, A.; Dimmeler, S., Role of microRNAs in vascular diseases, inflammation, and angiogenesis. Cardiovasc Res 2008, 79 (4), 581-8. https://www.ncbi.nlm.nih.gov/pubmed/18550634

81. Feng, J.; Li, A.; Deng, J.; Yang, Y.; Dang, L.; Ye, Y.; Li, Y.; Zhang, W., miR21 attenuates lipopolysaccharide-induced lipid accumulation and inflammatory response: potential role in cerebrovascular disease. Lipids Health Dis 2014, 13,27. DOI: $10.1186 / 1476-511 X-13-27$

82. Haver, V. G.; Slart, R. H.; Zeebregts, C. J.; Peppelenbosch, M. P.; Tio, R. A., Rupture of vulnerable atherosclerotic plaques: microRNAs conducting the orchestra? Trends Cardiovasc Med 2010, 20 (2), 65-71. https://www.ncbi.nlm.nih.gov/pubmed/20656218

83. Kulshreshtha, R.; Davuluri, R. V.; Calin, G. A.; Ivan, M., A microRNA component of the hypoxic response. Cell Death Differ 2008, 15 (4), 667-71. https://www.ncbi.nlm.nih.gov/pubmed/18219318 
84. Banzhaf-Strathmann, J.; Edbauer, D., Good guy or bad guy: the opposing roles of microRNA $125 \mathrm{~b}$ in cancer. Cell Commun Signal 2014, 12, 30. https://www.ncbi.nlm.nih.gov/pubmed/24774301

85. Sun, Y-M.; Lin, K-Y.; Chen, Y-Q., Diverse Functions of miR-125 family in different cell context. Journal of Hematology \& oncology 2013, 6,6. DOI: $\underline{110.1186 / 1756-8722-6-6}$

86. Ding, X. Q.; Ge, P. C.; Liu, Z.; Jia, H.; Chen, X.; An, F. H.; Li, L. H.; Chen, Z. H.; Mao, H. W.; Li, Z. Y.; Gu, Y.; Zhu, T. B.; Li, C. J.; Wang, L. S.; Ma, W. Z.; Yang, Z. J.; Jia, E. Z., Interaction between microRNA expression and classical risk factors in the risk of coronary heart disease. Sci Rep 2015, 5, 14925. https://www.ncbi.nlm.nih.gov/pubmed/26446730

87. Li, X.; Yao, N.; Zhang, J.; Liu, Z., MicroRNA-125b is involved in atherosclerosis obliterans in vitro by targeting podocalyxin. Mol Med Rep 2015, 12 (1), 561-8. https://www.ncbi.nlm.nih.gov/pubmed/25738314

88. Hueso, M.; De Ramon, L.; Navarro, E.; Ripoll, E.; Cruzado, J. M.; Grinyo, J. M.; Torras, J., Silencing of CD40 in vivo reduces progression of experimental atherogenesis through an NF- $\mathrm{BB} / \mathrm{miR}-125 \mathrm{~b}$ axis and reveals new potential mediators in the pathogenesis of atherosclerosis. Atherosclerosis 2016, 255, 80-89. https://www.ncbi.nlm.nih.gov/pubmed/27835742

89. Kellis, M.; Wold, B.; Snyder, M. P.; Bernstein, B. E.; Kundaje, A.; Marinov, G. K.; Ward, L. D.; Birney, E.; Crawford, G. E.; Dekker, J.; Dunham, I.; Elnitski, L. L.; Farnham, P. J.; Feingold, E. A.; Gerstein, M.; Giddings, M. C.; Gilbert, D. M.; Gingeras, T. R.; Green, E. D.; Guigo, R.; Hubbard, T.; Kent, J.; Lieb, J. D.; Myers, R. M.; Pazin, M. J.; Ren, B.; Stamatoyannopoulos, J. A.; Weng, Z.; White, K. P.; Hardison, R. C., Defining functional DNA elements in the human genome. Proc Natl Acad Sci U S A 2014, 111 (17), 6131-8. DOI: 10.1073/pnas.1318948111

90. Solyom, S.; Kazazian, H. H., Mobile elements in the human genome: implications for disease. Genome Med 2012, 4 (2), 12 . < https://www.ncbi.nlm.nih.gov/pubmed/22364178

91. Cowley, M.; Oakey, R. J., Transposable elements re-wire and fine-tune the transcriptome. PLoS Genet 2013, $9 \quad$ (1), e1003234. https://www.ncbi.nlm.nih.gov/pubmed/23358118

92. Gu, Z.; Jin, K.; Crabbe, M. J.; Zhang, Y.; Liu, X.; Huang, Y.; Hua, M.; Nan, P.; Zhang, Z.; Zhong, Y., Enrichment analysis of Alu elements with different spatial chromatin proximity in the human genome. Protein Cell 2016, 7 (4), 250-66. 
https://www.ncbi.nlm.nih.gov/pubmed/26861146

93. Hambor, J. E.; Mennone, J.; Coon, M. E.; Hanke, J. H.; Kavathas, P., Identification and characterization of an Alu-containing, T-cell-specific enhancer located in the last intron of the human CD8 alpha gene. Mol Cell Biol 1993, 13 (11), 7056-70. https://www.ncbi.nlm.nih.gov/pubmed/8413295

94. Hanke, J. H.; Hambor, J. E.; Kavathas, P., Repetitive Alu elements form a cruciform structure that regulates the function of the human CD8 alpha $\mathrm{T}$ cell-specific $\begin{array}{lllllll}\text { enhancer. } & J & \text { Mol Biol 1995, } & 246 & \text { (1), } & \text { 63-73. }\end{array}$ https://www.ncbi.nlm.nih.gov/pubmed/7853405

95. Trujillo, M. A.; Sakagashira, M.; Eberhardt, N. L., The human growth hormone gene contains a silencer embedded within an Alu repeat in the 3'-flanking region. $\begin{array}{lllll}\text { Mol Endocrinol 2006, } & \text { 2006-75. }\end{array}$ https://www.ncbi.nlm.nih.gov/pubmed/16762973

96. Ichiyanagi, K., Transposable elements in eukaryotic genomes: epigenetic regulation by the host and functionalization for the host. Genes Genet Syst 2013, 88 (1), 1. https://www.ncbi.nlm.nih.gov/pubmed/23676704

97. Bouttier, M.; Laperriere, D.; Memari, B.; Mangiapane, J.; Fiore, A.; Mitchell, E.; Verway, M.; Behr, M. A.; Sladek, R.; Barreiro, L. B.; Mader, S.; White, J. H., Alu repeats as transcriptional regulatory platforms in macrophage responses to $\mathrm{M}$. tuberculosis infection. Nucleic Acids Res 2016, 44 (22), 10571-10587. https://www.ncbi.nlm.nih.gov/pubmed/27604870

98. Zuckerkandl, E.; Latter, G.; Jurka, J., Maintenance of function without selection: Alu sequences as "cheap genes". J Mol Evol 1989, 29 (6), 504-12. https://www.ncbi.nlm.nih.gov/pubmed/2515297

99. Ade, C.; Roy-Engel, A. M.; Deininger, P. L., Alu elements: an intrinsic source of human genome instability. Curr Opin Virol 2013, 3 (6), 639-45. https://www.ncbi.nlm.nih.gov/pubmed/24080407

100. Payer, L. M.; Steranka, J. P.; Yang, W. R.; Kryatova, M.; Medabalimi, S.; Ardeljan, D.; Liu, C.; Boeke, J. D.; Avramopoulos, D.; Burns, K. H., Structural variants caused by Alu insertions are associated with risks for many human diseases. Proc Natl Acad Sci $U \quad S \quad A \quad$ 2017, 114 (20), E3984-E3992. https://www.ncbi.nlm.nih.gov/pubmed/28465436

101. Chen, J.; Huan, W.; Zuo, H.; Zhao, L.; Huang, C.; Liu, X.; Hou, S.; Qi, J.; Shi, 
W., Alu methylation serves as a biomarker for non-invasive diagnosis of glioma.
Oncotarget
2016,
7
(18),
26099-106.

https://www.ncbi.nlm.nih.gov/pubmed/27028997

102. Kolomietz, E.; Meyn, M. S.; Pandita, A.; Squire, J. A., The role of Alu repeat clusters as mediators of recurrent chromosomal aberrations in tumors. Genes $\begin{array}{lllll}\text { Chromosomes } & \text { Cancer } & \mathbf{2 0 0 2}, & 35 & \text { (2), }\end{array}$ https://www.ncbi.nlm.nih.gov/pubmed/12203773

103. Wallace, M. R.; Andersen, L. B.; Saulino, A. M.; Gregory, P. E.; Glover, T. W.; Collins, F. S., A de novo Alu insertion results in neurofibromatosis type 1. Nature 1991, 353 (6347), 864-6. https://www.ncbi.nlm.nih.gov/pubmed/1719426

104. Chae, J. J.; Park, Y. B.; Kim, S. H.; Hong, S. S.; Song, G. J.; Han, K. H.; Namkoong, Y.; Kim, H. S.; Lee, C. C., Two partial deletion mutations involving the same Alu sequence within intron 8 of the LDL receptor gene in Korean patients with familial hypercholesterolemia. Hum Genet 1997, 99 (2), 155-63. https://www.ncbi.nlm.nih.gov/pubmed/9048913

105. Ricci, V.; Regis, S.; Di Duca, M.; Filocamo, M., An Alu-mediated rearrangement as cause of exon skipping in Hunter disease. Hum Genet 2003, 112 (4), 419-25. https://www.ncbi.nlm.nih.gov/pubmed/12579417

106. Sen, S. K.; Han, K.; Wang, J.; Lee, J.; Wang, H.; Callinan, P. A.; Dyer, M.; Cordaux, R.; Liang, P.; Batzer, M. A., Human genomic deletions mediated by recombination between Alu elements. Am J Hum Genet 2006, 79 (1), 41-53. https://www.ncbi.nlm.nih.gov/pubmed/16773564

107. Holdt, L. M.; Teupser, D., From genotype to phenotype in human atherosclerosis--recent findings. Curr Opin Lipidol 2013, 24 (5), 410-8. https://www.ncbi.nlm.nih.gov/pubmed/24005217

108. Visel, A.; Zhu, Y.; May, D.; Afzal, V.; Gong, E.; Attanasio, C.; Blow, M. J.; Cohen, J. C.; Rubin, E. M.; Pennacchio, L. A., Targeted deletion of the 9p21 noncoding coronary artery disease risk interval in mice. Nature 2010, 464 (7287), 40912. https://www.ncbi.nlm.nih.gov/pubmed/20173736

109. He, S.; Gu, W.; Li, Y.; Zhu, H., ANRIL/CDKN2B-AS shows two-stage cladespecific evolution and becomes conserved after transposon insertions in simians. BMC Evol Biol 2013, 13, 247. https://www.ncbi.nlm.nih.gov/pubmed/24225082

110. Tsirigos, A.; Rigoutsos, I., Alu and b1 repeats have been selectively retained in the upstream and intronic regions of genes of specific functional classes. PLoS 


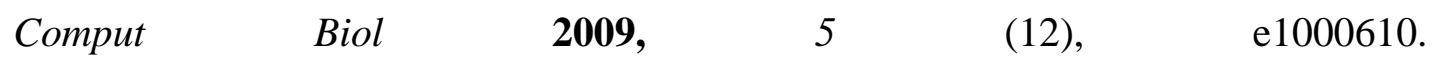

https://www.ncbi.nlm.nih.gov/pubmed/20019790

111. Burenina, O.Y.; Oretskaya, T.S.; Kubareva, E.A., Non-coding RNAs as Transcriptional Regulators in Eukaryotes. Acta Naturae 2017, 9 (4): 13-25. https://www.ncbi.nlm.nih.gov/pmc/issues/304560/

112. Gu, T. J.; Yi, X.; Zhao, X. W.; Zhao, Y.; Yin, J. Q., Alu-directed transcriptional regulation of some novel miRNAs. BMC Genomics 2009, 10, 563. https://www.ncbi.nlm.nih.gov/pubmed/19943974

113. Borchert, G. M.; Lanier, W.; Davidson, B. L., RNA polymerase III transcribes human microRNAs. Nat Struct Mol Biol 2006, 13 (12), 1097-101. https://www.ncbi.nlm.nih.gov/pubmed/17099701

114. Monteys, A. M.; Spengler, R. M.; Wan, J.; Tecedor, L.; Lennox, K. A.; Xing, Y.; Davidson, B. L., Structure and activity of putative intronic miRNA promoters. RNA 2010, 16 (3), 495-505. DOI:10.1261/rna.1731910

115. Smalheiser, N. R.; Torvik, V. I., Alu elements within human mRNAs are probable microRNA targets. Trends Genet 2006, 22 (10), 532-6. https://www.ncbi.nlm.nih.gov/pubmed/16914224

116. Daskalova, E.; Baev, V.; Rusinov, V.; Minkov, I., 3'UTR-located ALU elements: donors of potential miRNA target sites and mediators of network miRNAbased regulatory interactions. Evol Bioinform Online 2007, 2, 103-20. https://www.ncbi.nlm.nih.gov/pubmed/19455205

117. Di Ruocco, F.; Basso, V.; Rivoire, M.; Mehlen, P.; Ambati, J.; De Falco, S.; Tarallo, V., Alu RNA accumulation induces epithelial-to-mesenchymal transition by modulating miR-566 and is associated with cancer progression. Oncogene 2017. DOI: $10.1038 /$ onc. 2017.369

118. Pandey, R.; Bhattacharya, A.; Bhardwaj, V.; Jha, V.; Mandal, A. K.; Mukerji, M., Alu-miRNA interactions modulate transcript isoform diversity in stress response and reveal signatures of positive selection. Sci Rep 2016, 6, 32348. https://www.ncbi.nlm.nih.gov/pubmed/27586304

119. Hoffman, Y.; Bublik, D. R.; Pilpel, Y.; Oren, M., miR-661 downregulates both Mdm2 and Mdm4 to activate p53. Cell Death Differ 2014, 21 (2), 302-9. https://www.ncbi.nlm.nih.gov/pubmed/24141721

120. Hernández-Presa, M.; Bustos, C.; Ortego, M.; Tuñon, J.; Renedo, G.; Ruiz- 
Ortega, M.; Egido, J., Angiotensin-converting enzyme inhibition prevents arterial nuclear factor-kappa B activation, monocyte chemoattractant protein-1 expression, and macrophage infiltration in a rabbit model of early accelerated atherosclerosis. Circulation 1997, 95 (6), 1532-41. https://www.ncbi.nlm.nih.gov/pubmed/9118522

121. Zhang, W.; Xing, S. S.; Sun, X. L.; Xing, Q. C., Overexpression of activated nuclear factor-kappa B in aorta of patients with coronary atherosclerosis. Clin Cardiol 2009, 32 (12), E42-7. https://www.ncbi.nlm.nih.gov/pubmed/20014193

122. Hueso, M.; Torras, J.; Carrera, M.; Vidal, A.; Navarro, E.; Grinyó, J., Chronic Kidney Disease is associated with an increase of Intimal Dendritic cells in a comparative autopsy study. J Inflamm (Lond) 2015, 12, 26. https://www.ncbi.nlm.nih.gov/pubmed/25861247

123. Vallabhapurapu, S.; Karin, M., Regulation and function of NF-kappaB transcription factors in the immune system. Annu Rev Immunol 2009, 27, 693-733. https://www.ncbi.nlm.nih.gov/pubmed/19302050

124. Farnham, P. J., Insights from genomic profiling of transcription factors. Nat Rev Genet 2009, 10 (9), 605-16. DOI: 10.1038/nrg2636.

125. Antonaki, A.; Demetriades, C.; Polyzos, A.; Banos, A.; Vatsellas, G.; Lavigne, M. D.; Apostolou, E.; Mantouvalou, E.; Papadopoulou, D.; Mosialos, G.; Thanos, D., Genomic analysis reveals a novel nuclear factor- $\kappa \mathrm{B}(\mathrm{NF}-\kappa \mathrm{B})$-binding site in Alu-repetitive elements. $J$ Biol Chem 2011, 286 (44), 38768-82. https://www.ncbi.nlm.nih.gov/pubmed/21896491

126. Kasowski, M.; Grubert, F.; Heffelfinger, C.; Hariharan, M.; Asabere, A.; Waszak, S. M.; Habegger, L.; Rozowsky, J.; Shi, M.; Urban, A. E.; Hong, M. Y.; Karczewski, K. J.; Huber, W.; Weissman, S. M.; Gerstein, M. B.; Korbel, J. O.; Snyder, M., Variation in transcription factor binding among humans. Science 2010, 328 (5975), 232-5. https://www.ncbi.nlm.nih.gov/pubmed/20299548

127. Ruiz-Ortega, M.; Lorenzo, O.; Rupérez, M.; Esteban, V.; Suzuki, Y.; Mezzano, S.; Plaza, J. J.; Egido, J., Role of the renin-angiotensin system in vascular diseases: expanding the field. Hypertension 2001, $38 \quad$ (6), 1382-7. https://www.ncbi.nlm.nih.gov/pubmed/11751722

128. Sahar, S.; Dwarakanath, R.; Reddy, M.; Lanting, L.; Todorov, I.; Natarajan, R.; Angiotensin II enhances interleukin-18 mediated inflammatory gene expression in vascular smooth Muscle cells-A novel Cross-Talk in the Pathogenesis of Atherosclerosis. Circ Res 2005: 96:1064-1071. DOI: 10.1161/01.RES.0000168210.10358.f4 
129. Pfeffer, M. A.; Braunwald, E.; Moyé, L. A.; Basta, L.; Brown, E. J.; Cuddy, T. E.; Davis, B. R.; Geltman, E. M.; Goldman, S.; Flaker, G. C., Effect of captopril on mortality and morbidity in patients with left ventricular dysfunction after myocardial infarction. Results of the survival and ventricular enlargement trial. The SAVE Investigators. $N$ Engl $J$ Med 1992, 327 (10), 669-77. https://www.ncbi.nlm.nih.gov/pubmed/1386652

130. Hueso, M.; Alía, P.; Moreso, F.; Beltrán-Sastre, V.; Riera, L.; González, C.; Navarro, M. A.; Grinyó, J. M.; Navarro, E.; Serón, D., Angiotensin converting enzyme genotype and chronic allograft nephropathy in protocol biopsies. J Am Soc Nephrol 2004, 15 (8), 2229-36. https://www.ncbi.nlm.nih.gov/pubmed/15284309

131. Cambien, F.; Poirier, O.; Lecerf, L.; Evans, A.; Cambou, J. P.; Arveiler, D.; Luc, G.; Bard, J. M.; Bara, L.; Ricard, S., Deletion polymorphism in the gene for angiotensin-converting enzyme is a potent risk factor for myocardial infarction. Nature 1992, 359 (6396), 641-4. https://www.ncbi.nlm.nih.gov/pubmed/1328889

132. Rigat, B.; Hubert, C.; Alhenc-Gelas, F.; Cambien, F.; Corvol, P.; Soubrier, F., An insertion/deletion polymorphism in the angiotensin I-converting enzyme gene accounting for half the variance of serum enzyme levels. J Clin Invest 1990, 86 (4), 1343-6. https://www.ncbi.nlm.nih.gov/pubmed/1976655

133. Woods, D. R.; Brull, D.; Montgomery, H. E., Endurance and the ACE I/D polymorphism. Sci Prog 2000, $83 \quad$ (Pt 4), 317-36. https://www.ncbi.nlm.nih.gov/pubmed/11233367

134. Wu, S. J.; Hsieh, T. J.; Kuo, M. C.; Tsai, M. L.; Tsai, K. L.; Chen, C. H.; Yang, Y. H., Functional regulation of Alu element of human angiotensin-converting enzyme gene in neuron cells. Neurobiol Aging 2013, 34 (7), 1921.e1-7. DOI:10.1016/j.neurobiolaging.2013.01.003

135. Sayed-Tabatabaei, F. A.; Oostra, B. A.; Isaacs, A.; van Duijn, C. M.; Witteman, J. C., ACE polymorphisms. Circ Res 2006, 98 (9), 1123-33. DOI:10.1161/01.RES.0000223145.74217.e7

136. Yan, Q., From pharmacogenomics and systems biology to personalized care: a framework of systems and dynamical medicine. Methods Mol Biol 2014, 1175, 317. DOI: $\underline{10.1007 / 978-1-4939-0956-8 \_1}$

137. Derry, P. S.; Derry, G. N., Menstruation, perimenopause, and chaos theory. $\begin{array}{lllll}\text { Perspect Biol } & \text { Med } & \text { 2012, } & 55 & \text { (1), }\end{array}$ https://www.ncbi.nlm.nih.gov/pubmed/22643714. 
138. Badimon, L.; Vilahur, G., LDL-cholesterol versus HDL-cholesterol in the atherosclerotic plaque: inflammatory resolution versus thrombotic chaos. Ann NY Acad Sci 2012, 1254, 18-32. https://www.ncbi.nlm.nih.gov/pubmed/22548566

139. Mangin, L.; Lesèche, G.; Duprey, A.; Clerici, C., Ventilatory chaos is impaired in carotid atherosclerosis. PLoS One 2011, 6 (1), e16297. DOI: 10.1371/journal.pone.0016297

140. Martín-Araguz, A.; Ruiz-Aláez, A.; García de la Rocha, M. L.; FernándezArmayor, V.; Delgado-Reyes, S.; Moreno-Martínez, J. M., [Kinematic deterministic chaos of fluids and fractal geometry in the carotid system]. Rev Neurol 1997, 25 (148), 2021-31. https://www.ncbi.nlm.nih.gov/pubmed/9528050.

141. Sun, L.H,; Frankel, F.R.; The induction of ALU-sequence transcripts by glucocorticoid in rat liver cells. Journal of Steroid Biochemistry 1986, 25(2):201207. DOI: $\underline{10.1016 / 0022-4731(86) 90417-6}$

142. Koga, Y,; Lindstrom, E,; Fenyo, E.M,; Wigzell, H,; Mak, T,. High levels of heterodisper RNA accumulate in T-cell infected with human immunodeficiency virus and in normal thymocytes. Proc Natl Acad Sci U S A 1988, 85:4521-5. https://www.ncbi.nlm.nih.gov/pmc/articles/PMC280462/

143. Panning, B,; Smiley, J.R,; Activation of RNA polymerase III transcription of human Alu repetitive elements by adenovirus type 5: requirement for the E1b 58kilodalton protein and the products of E4 open reading frames 3 and 6. Mol Cell Biol 1993, 13: 3231-44. https://www.ncbi.nlm.nih.gov/pmc/articles/PMC359768/

144. Russanova, V.R,; Driscoll, C.T,; Howard, B.H, Adenovirus type 2 preferentially stimulates polymerase III transcription af Alu elements by relieving repression: a potential role for chromatin. Mol Cell Biol 1995, 8: 4282-90. https://www.ncbi.nlm.nih.gov/pmc/articles/PMC230667/

145. Panning, B,; Smiley, J.R,; Activation of RNA polymerase III transcription of human Alu elements by herpes simplex virus. Virology 1994, 202:408-17. DOI: $\underline{10.1006 / \text { viro.1994.1357 }}$

146. Kim, C,; Rubin, C.M,; Schmid, C.W.; Genome-wide chromatin remodeling modulates the Alu heat shock response. Gene 2001, 276: 127-33. DOI: $\underline{10.1016 / \mathrm{S} 0378-1119(01) 00639-4}$ 


\section{FIGURE LEGENDS}

Figure 1. Structural features of Alu repeated sequences.

Shown are the distinctive elements that conform an Alu monomer. The two arms linked by an A-rich sequence, the bipartite A,B boxes) Pol III promoter and the poly-A tail. Graphic not drawn to scale.

Figure 2. Possible mechanisms by which Alu repeated sequences impact on ATH progression.

(A). Alu elements regulate the function of ANRIL, the strongest risk factor for atherosclerosis and CVD.

ANRIL RNA, which harbors Alu elements, is transcribed and recruits the Polycomb Repressive Complexes 1 and 2 and interacts with other genes via an "Alu/Alu" or "Alu/other site" direct interaction, thus facilitating PRC1/2 to regulate their expression. Taken from [56]. Graphic not drawn to scale.

(B). Alu-RNAs could behave as miRNAs sponges to create complex regulatory networks that are altered in disease.

Shown are the main elements implicated in the Alu/miRNA regulatory loop: Alu genes, free Alu-RNAs, miRNA genes and miRNAs. The postulated Alu/miRNA interaction does not consider the folding of the Alu elements nor the existance of Alu [miRNA] binding proteins that could impact on the interaction. STRESS stands for any stimuli that upregulates transcription of free Alu elements as glucocorticoids [141], HIV infection [142], adenovirus type 5 [143], or type 2 infection [144], herpex simplex virus infection [145] or heat-shock [146].Graphic not drawn to scale.

(C). Several Alu elements are binding sites for transcription factors such as NF-kb and may impact on gene expression of the inflammatory response.

Retrogressed Alu elements can function as NF- $\mathrm{kb}$ binding sites thus expanding the set of genes co-regulated by NF-kb in the inflammatory response (se main text for details). Shown are the main elements implicated in the Alu/ NF-kb regulatory loop: Alu genes, free Alu-RNAs, Alu cDNAs and their retrogression to gene regulatory regions. STRESS definition as in (B). Graphic not drawn to scale. 
STRUCTURE OF AN ALU REPEATED ELEMENT (MONOMER)

1

$300 \mathrm{bp}$

LEFT ALU RNA

RIGHT ALU RNA

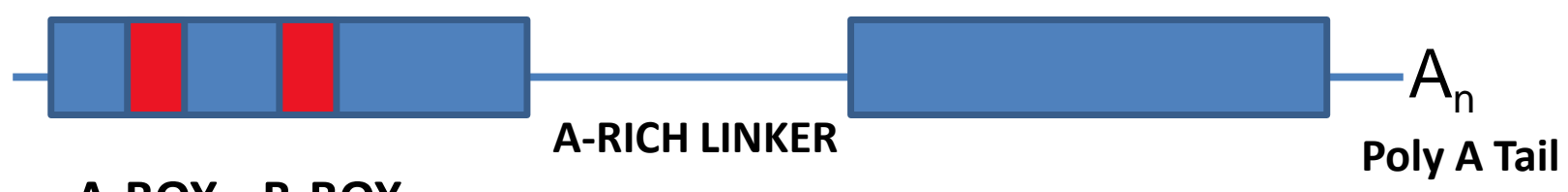

$\frac{\text { A-BOX B-BOX }}{\text { POLIII PROMOTER }}$

FIGURE 1 

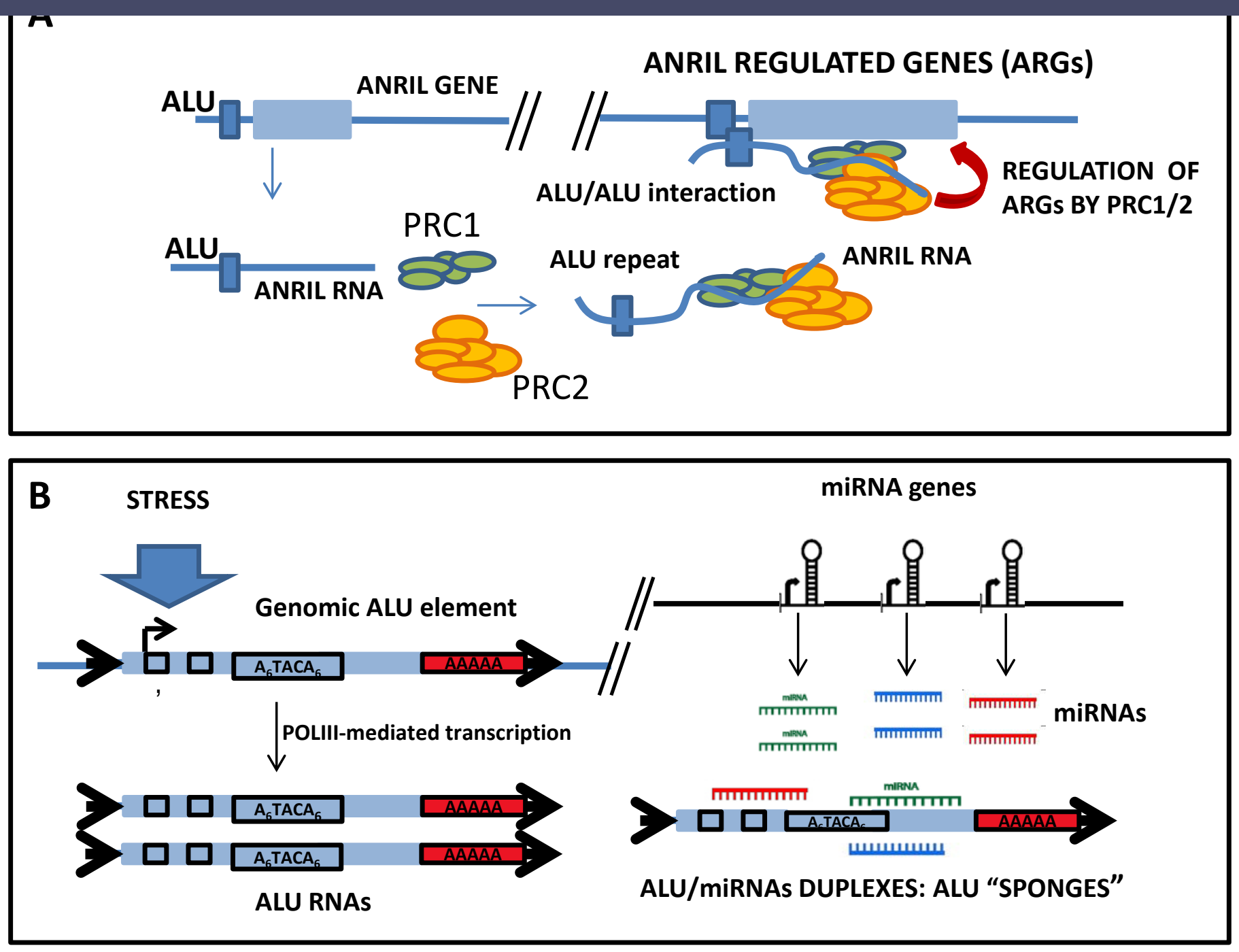

C

\section{STRESS}

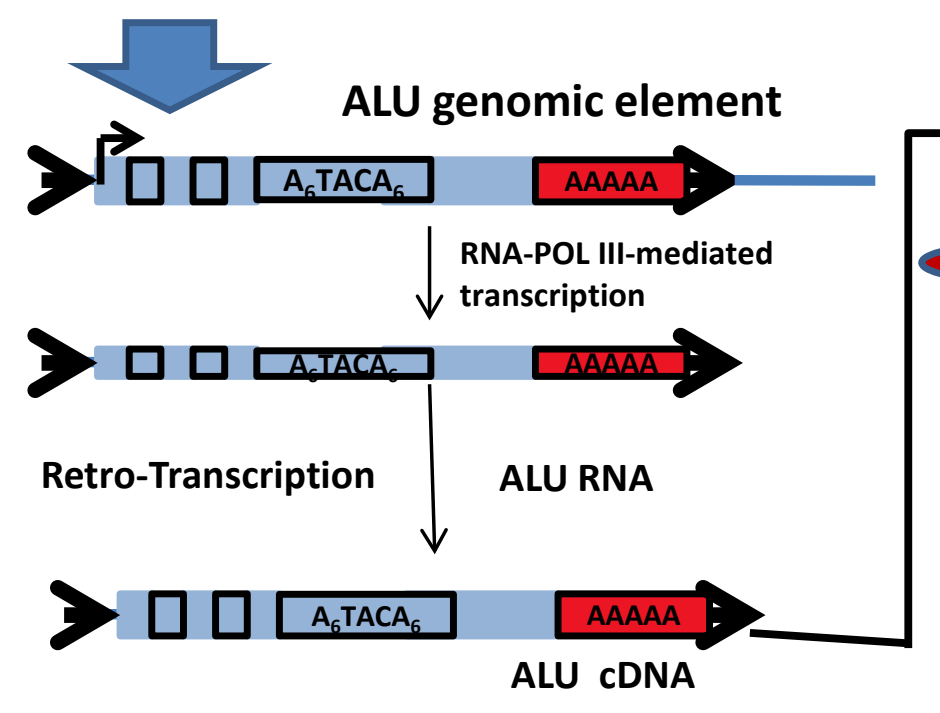

Retro-INSERTION
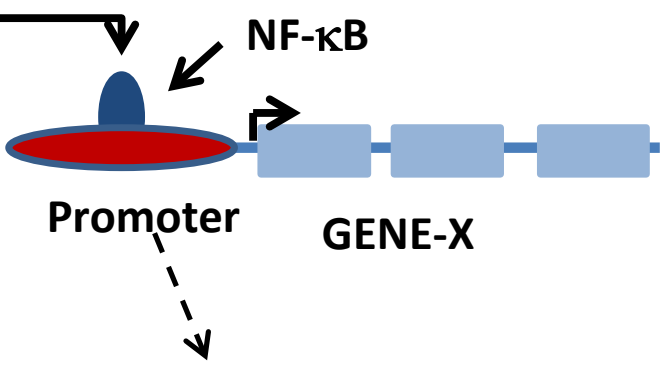

NEW ALU-DERIVED REGULATORY SITE (ALU-kB) 